\title{
Correction to: Optimisation of a screening platform for determining IL-6 inflammatory signalling in the senescence-associated secretory phenotype (SASP)
}

Adam Rolt $($ D $\cdot$ Anitha Nair - Lynne S. Cox $(\mathbb{D}$

Published online: 6 March 2019

(C) The Author(s) 2019

Correction to: Biogerontology

https://doi.org/10.1007/s10522-019-09796-4

In the original publication of the article, Fig. 2 was published incorrectly. The corrected Fig. 2 is given below. The original article has been corrected.

The original article can be found online at https://doi.org/10.1007/s10522-019-09796-4.

\footnotetext{
A. Rolt · A. Nair · L. S. Cox $(\bowtie)$

Department of Biochemistry, University of Oxford, South

Parks Road, Oxford OX1 3QU, UK

e-mail: lynne.cox@bioch.ox.ac.uk
} 
A

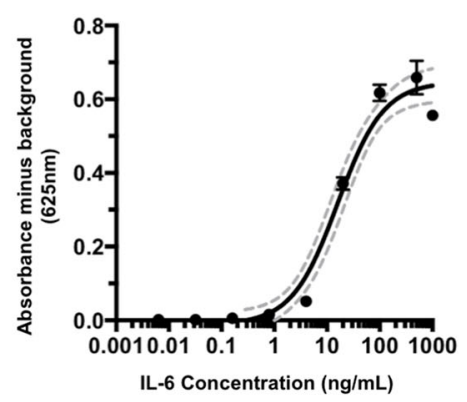

C (i)

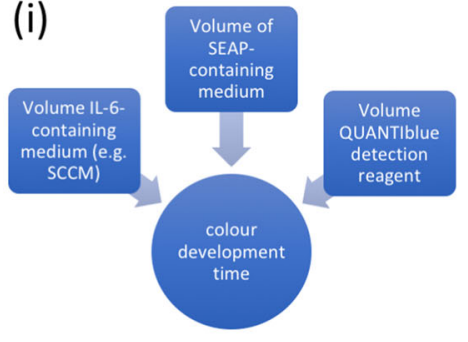

D
B

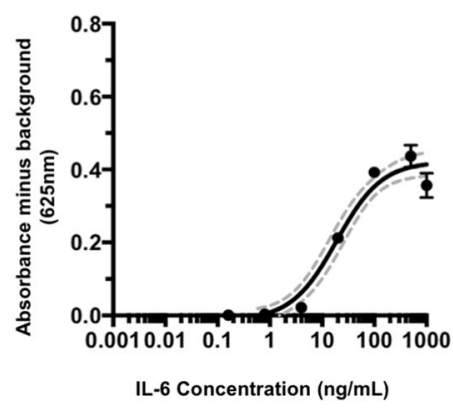

(ii)

\begin{tabular}{|l|l|l|}
\hline well & $\begin{array}{l}\text { Vol } \\
\text { SEAP } \\
(\mu \mathrm{L})\end{array}$ & $\begin{array}{l}\text { Vol } \\
\mathrm{QB} \\
(\mu \mathrm{L})\end{array}$ \\
\hline $\mathrm{A}$ & 5 & 45 \\
\hline B & 15 & 35 \\
\hline C & 25 & 25 \\
\hline $\mathrm{D}$ & 35 & 15 \\
\hline
\end{tabular}

(iii)

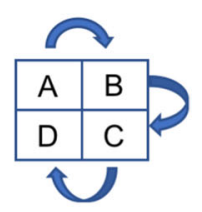

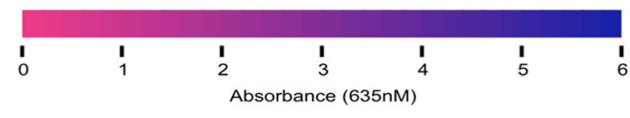

IL-6 Concentration (ng/mL)

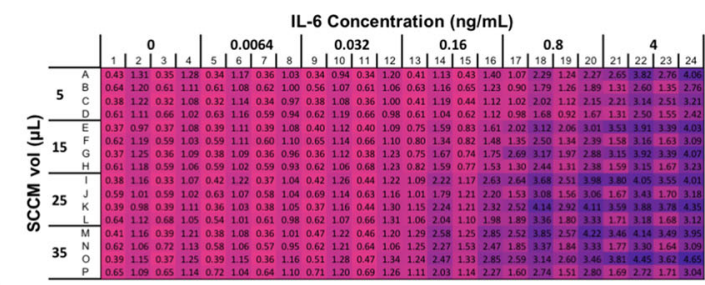

E
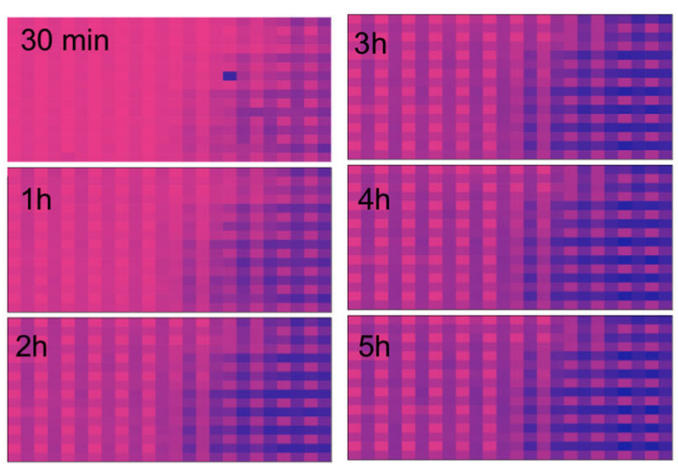

\section{F}

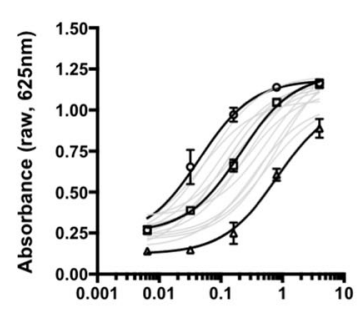

G

IL-6 Concentration

(ng/mL)

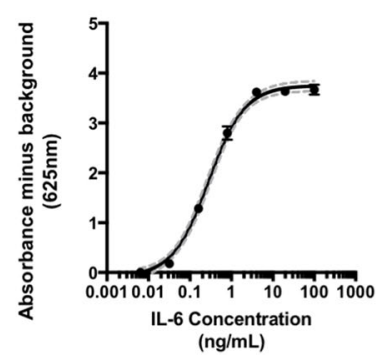


4Fig. 2 Optimisation of HEK-Blue ${ }^{\mathrm{TM}}$ IL-6 assay to detect physiological levels of IL-6. a Standard curve produced in a 96 well plate from a dilution series of recombinant human IL-6 $(n=$ 2 plate replicates per concentration, with in-plate triplicates, standard deviations and 95\% confidence interval shown). Conditions: 50000 HEK-Blue cells per well, $20 \mu \mathrm{L}$ of IL-6 sample, final volume $200 \mu \mathrm{L}$. b Standard curve produced in a 384 well plate from a dilution series of recombinant human IL-6 $(\mathrm{n}=2$ plate replicates per concentration, with in-plate triplicates, standard deviations and $95 \%$ confidence intervals shown). Conditions: 12,500 cells per well, $5 \mu \mathrm{L}$ of IL- 6 sample, final volume $50 \mu \mathrm{L}$. c Schematic demonstrating optimisation protocol for HEK-SASP (i) the 4 variables tested in parallel were volume of SCCM added to HEK-Blue cells, volume of SEAPcontaining medium (i.e. medium conditioned by HEKBlueTMcells), volume of QUANTI-Blue detection reagent, and colour development time for the final QB step of the assay; (ii) ratios of SEAP-containing medium to QUANTI-Blue detection reagent $(\mathrm{QB})$ tested in 4 adjacent wells; (iii) pipetting of the different ratios of media in (ii) was achieved using a 96-well pipettor, with the plate shifted by one well position to the right, down or left (as shown) for each sequential pipetting reaction, leading to a quadrant format in the 384 well plate. d Colour coded 384 well plate with quantitative values, showing quadrant arrangement of samples. e Colour-coded data from incubation time course. f Standard curves generated from the various combinations of variables described in (c) and (d). g Standard curve from optimised protocol: 384 well plate, 12,500 HEKBlue $^{\mathrm{TM}}$ IL-6 cells per well, $15 \mu \mathrm{L}$ of sample (SCCM or recombinant human IL-6) to a final volume of $50 \mu \mathrm{L}$. $15 \mu \mathrm{L}$ of SEAP medium was transferred to $35 \mu \mathrm{L}$ of QUANTI-Blue and incubated for $2 \mathrm{~h}$ at $37{ }^{\circ} \mathrm{C}$ in a humidified incubator at $5 \% \mathrm{CO}_{2}$. For each curve, continuous line $=$ mean of triplicates at each concentration within a single plate, dotted lines $=95 \%$ confidence intervals
Open Access This article is distributed under the terms of the Creative Commons Attribution 4.0 International License (http:// creativecommons.org/licenses/by/4.0/), which permits unrestricted use, distribution, and reproduction in any medium, provided you give appropriate credit to the original author(s) and the source, provide a link to the Creative Commons license, and indicate if changes were made.

Publisher's Note Springer Nature remains neutral with regard to jurisdictional claims in published maps and institutional affiliations. 